\title{
What can nanosafety learn from drug development? The feasibility of "safety by design"
}

Hjorth, Rune; van Hove, Lilian; Wickson, Fern

\section{Published in:}

Nanotoxicology

Link to article, DOI:

10.1080/17435390.2017.1299891

Publication date:

2017

Document Version

Peer reviewed version

Link back to DTU Orbit

Citation (APA):

Hjorth, R., van Hove, L., \& Wickson, F. (2017). What can nanosafety learn from drug development? The feasibility of "safety by design". Nanotoxicology, 11(3), 305-312.

https://doi.org/10.1080/17435390.2017.1299891

\section{General rights}

Copyright and moral rights for the publications made accessible in the public portal are retained by the authors and/or other copyright owners and it is a condition of accessing publications that users recognise and abide by the legal requirements associated with these rights.

- Users may download and print one copy of any publication from the public portal for the purpose of private study or research.

- You may not further distribute the material or use it for any profit-making activity or commercial gain

- You may freely distribute the URL identifying the publication in the public portal

If you believe that this document breaches copyright please contact us providing details, and we will remove access to the work immediately and investigate your claim. 


\title{
What can nanosafety learn from drug development? The feasibility of 'Safety by design'
}

Rune Hjorth $^{1^{*}}$, Lilian van Hove ${ }^{2}$ and Fern Wickson ${ }^{2}$

*Corresponding author ruhj@env.dtu.dk

${ }^{1}$ Department of Environmental Engineering, Technical University of Denmark, Kgs. Lyngby, Denmark

${ }^{2}$ Society, Ecology and Ethics Department, GenØk Centre for Biosafety, Tromsø, Norway

\begin{abstract}
'Safety by design' (SbD) is an intuitively appealing concept that is on the rise within nanotoxicology and nanosafety research, as well as within nanotechnology research policy. It leans on principles established within drug discovery and development (DDD) and seeks to address safety early, as well as throughout product development. However, it remains unclear what the concept of SbD exactly entails for engineered nanomaterials (ENMs) or how it is envisioned to be implemented. Here we review the concept as it is emerging in European research and compare its resemblance with the safety testing and assessment practices in DDD. From this comparison, it is clear that 'safety' is not obtained through DDD, and that SbD should be considered a starting point rather than an end, meaning that products will still need to progress through thorough safety evaluations and regulation. We conclude that although risk reduction is clearly desirable, the way SbD is currently communicated tends to treat safety as an inherent material property and that this is fundamentally problematic as it represents a recasting and reduction of societal issues into technical problems. SbD therefore faces a multitude of challenges, from practical implementation to unrealistic stakeholder expectations.
\end{abstract}

Keywords: Safety by Design, Nanotoxicology, Drug development, Nanosafety 


\section{Introduction}

In July 2016, the European Nanosafety Cluster's (NSC) annual report on the status of EU funded projects on nanosafety was released. It highlights that within these EU projects there is an 'increasing focus on safety-by-design consideration for nanomaterials' (Lynch, 2016) and 'the focus of investment and research has moved increasingly towards predictive and high throughput approaches to nanosafety, including safety-by-design...' (NSC, 2016). Furthermore, the report states that this focus will intensify when the 3rd round of Horizon 2020 projects commences (Lynch, 2016). Although different ideas of safety by design (SbD) coexist, the basic concept refers to the process of anticipating potential impacts of a product or material on human and/or environmental health and preemptively addressing safety concerns early in the innovation process through altering product design.

Predictive toxicology and high throughput approaches are currently being pursued to facilitate the investigation of safety considerations and early decisionmaking on design choices by trying to elucidate the mode of action of engineered nanomaterials (ENMs), with the underlying assumption that there is a relationship between structure and activity and that mechanistic insight is needed to bridge the gap. By understanding this relationship, the vision is that we can predict the hazardousness of ENMs and design advanced materials to purposefully avoid unwanted properties while retaining desired functionality. Creating ENMs that are 'safer' or 'safe' by design is arguably inspired by processes in drug discovery and development (DDD) (Damoiseaux et al., 2011; Movia et al., 2014; NANoREG, 2015) and has been a touted aspiration ever since nanotoxicology began as a field of research (Kelty, 2009). 
Since establishing dedicated regulatory systems capable of adequately assessing the risks of ENMs 'downstream' from product development has proved problematic, considering safety as a characteristic that can be incorporated as a design parameter 'upstream' during product development is immediately appealing. Given that the regulatory situation for ENMs is still unclear and in development (Hansen and Baun, 2015), uncertainty concerning how to quantify and identify novel risks remains (Grieger, 2011, Johnston et al., 2013, Miller and Wickson, 2015, Saleh et al., 2015) and the pressing need for safety research to keep pace with innovation (Savolainen et al., 2013), the idea of safety by design seems to offer a particularly powerful approach to circumvent these obstacles.

While applying the concept of SbD to ENMs has gained increased attention around the world in recent years, it has a particularly notable and consistent presence in European approaches to nanomaterial research and innovation. This is evidenced through existing FP7 projects (Lynch, 2014, 2015, 2016) and the emphasis seems set to continue into Horizon 2020. However, since current European approaches are underpinned by the paradigm of first identifying risks and then designing for safety, uncertainties surrounding the feasibility of SbD remain. Despite its current prominence, the concept of SbD for nanomaterials as it appears in European research and policy remains superficial, under-conceptualized and largely unevaluated. Indeed, the issue of how to implement the concept in practice is rarely articulated and the feasibility of the concept to facilitate the development of safer products rarely questioned. This is despite the presence of significant challenges remaining on several levels.

Here we therefore provide a timely review of how the concept of SbD for ENMs is being presented and approached within European nanosafety research as 
well as an analysis of its major challenges. To do this, we specifically examine how the SbD concept is emerging for ENMs in Europe and consider how this compares with the current practice in DDD. Finally, we examine what lessons nanosafety can learn from DDD and highlight that, although safety is addressed throughout DDD, pharmaceuticals are not consequently considered safe. Indeed, as we will illustrate, treating safety as an inherent material property is fundamentally problematic and therefore it is important to revise existing expectations of what SbD can and can't do within nanosafety research and policy.

\section{What is Safety by design for Engineered Nanomaterials?}

The concept of designing for safety has been developed and applied in the engineering sector for decades, where the focus has been on addressing potential safety concerns and minimising risk through the design of engineered products (e.g. Brown, 1976; Wang et al., 1996). Within the construction industry, there has also been an emphasis on design modification as a way to prevent injuries on the work floor and reduce negative health effects for those constructing, using or maintaining a product. In recent years though, the concept of designing for safety has gained increased attention in fields such as 'green chemistry' and 'inherent safety', in which there is an attempt to design processes that have an intrinsically low level of hazard instead of managing hazards through protective systems.

Actively pursuing a safer design of ENMs has been proposed in a number of scientific reports, book chapters and articles over the last years (e.g. Meng et al., 2009; Tinkle 2010; ICON 2010; Morose 2010; Fadeel 2010, 2013; Riediker 2011; Truong et al., 2012; Nel et al., 2013; Som et al., 2013, Lynch et al., 2014; Geraci et al., 2015; Burello and Worth 2015; Costa, 2016). Recent empirical 
examples of applying SbD approaches to nanomaterial design include studies on $\mathrm{ZnO}$ particles (Le et al., 2016), CuO particles (Naatz et al., 2017), carbon nanotubes (Gilbertson et al., 2016), Au nanoboxes (Movia et al., 2014), $\mathrm{CeO}_{2}$ particles (Forest et al., 2017) and $\mathrm{SiO}_{2}$ particles (Lehman et al., 2016). As seen in Table 1, most European nanosafety projects incorporate - or see themselves as part of - SbD approaches to varying degrees. Although it is common for European nanosafety projects to refer to the concept of SbD, a close investigation reveals that these projects rarely engage in a detailed discussion of what is meant by SbD or discuss challenges for its implementation in practice. Indeed the meaning and practice of SbD seems to have received its most extensive articulation in the projects NANoREG and NANoREG II (Lynch, 2016).

\subsection{The NANoREG and NANoREG II Approach to Safety by design}

As of May 2015, the NANoREG SbD concept was published as a 32 page 'working document' on the NANoREG website (Sips et al., 2015), and stands to this day as the most comprehensive description available. Within NANoREG, emphasis has been placed on 'Safe-by-Design' as a way to develop new products where functionality and safety are tested in an integrated way during product or material development.

In its approach to the concept, the NANoREG project has specifically chosen to link SbD to a stage gate model of innovation. A stage gate model is effectively a conceptual and operational map used in innovation arenas for tracking, directing and managing the development of new products to market. Linking the SbD idea to the stage-gate innovation model provides some structure for the application of the concept in the context of the development of ENMs. However, it should also be noted that such stage-gate models have typically been employed for guiding innovation decisions within single companies or firms and may not necessarily be easily 
applicable for multi-actor networks and globally distributed value-chains, as can be the case for the development of ENMs and their incorporation into commercial products. The model for SbD from NANoREG presents the innovation process as consisting of various stages, each with its own requirements that need to be met in order for development to move on to the next stage. A gate then represents a decision point, or a control point, at which evaluation needs to occur, in this case on safety considerations and risk potentials, before product development can continue.

In the follow-up project, NANoREG II, three pillars of safe design, safe production, and safe use are to underpin a 'safe innovation' approach in which the SbD concept is combined with 'regulatory preparedness'. The latter is said to refer to a timely interaction between innovators and regulators, with the idea being that through focusing on safety issues early in the production and design process, as well as throughout the innovation chain, innovators are prepared with the information and knowledge they need to meet any regulatory requirements.

Creating safe EMNs in pillar 1 is described as achieved through understanding factors that influence 'risk potential' (namely characteristics such as solubility, coating stability, genotoxicity, ecotoxicity and potential to accumulate or create inflammation) and assessing knowledge on these using 'non-testing' tools such as structure activity relationships (SAR), grouping strategies and high throughput screening (HTS) of in vitro and in vivo tests to find 'less hazardous nanoforms'. However, NANoREG II also seeks to go beyond SbD to develop a 'Safe Innovation' approach and describes itself as 'built around the challenge of coupling SbD to the regulatory process' (Lynch, 2016). It also calls for proactive regulatory authorities (Sips et al., 2015), and a flexible regulatory system that allows for robust, yet costeffective and rapid regulation underpinned by SbD (Lynch, 2016). 


\section{Fundamental Challenges}

Despite the intuitive appeal of the idea of SbD, and its grounding in the engineering and construction sector, the details of its conceptual development and practical implementation for ENMs raises a number of questions and faces various obstacles that need to be explicitly acknowledged and addressed.

Safety is clearly a core value of the concept, although exactly what safety means can differ between fields, disciplines and individual perspectives. Indeed, safety is a relational value (i.e. to understand its meaning you first need to answer safety for whom or for what?). The challenges associated with this become particularly clear in the concept of environmental safety, where it is not immediately obvious what type of entities are of interest and deemed worthy of protecting (e.g. particular individual organisms, populations, species or ecosystems), nor how harm to particular individual organisms might be weighed against safety for collectives such as whole populations, species or ecosystems. Since absolute safety can never be guaranteed, SbD also begs questions relating to what is safe enough, who gets to define acceptable levels of safety, and how this decision-making is performed. For this reason, the use of 'safer' also seems more appropriate, than the more absolute 'safe' and 'safety'. However, as seen in Table 1, most of the current European projects utilize the latter terms, which is also reflected in the concept develop by NANoREG. Although NANoREG claims to recognize the impossibility of absolute safety (Sips et al., 2015), it still chooses to use the absolute terms safe and safety and fails to acknowledge the relational nature of the concept or the specific challenges involved in operationalizing its definition. Furthermore, by centralising the sole value on safety, the SbD concept fails to substantially engage with other potentially significant questions that can generate social debate or be of political relevance, such 
as how does the innovation align with social values, is it needed, is it ethically acceptable, and how does the innovation compare to other available alternatives for solving the same problem.

SbD clearly changes the typical risk evaluation question of 'is it safe?' to 'can we engineer it to be safe?' (Kelty 2009). The weight given to engineering and design implies that all safety concerns stem from the characteristics of the product rather than also being related to e.g. exposure and its context of use and deployment. SbD therefore threatens to take the political challenges of risk-based regulation (i.e. involving selecting values and protection goals during risk policy, interpreting science during risk assessment and taking political decisions during risk management) and reduces them to a technical engineering dilemma for scientists and innovators. In general, setting guiding values for a risk assessment, deciding on levels of risk acceptability, and deciding on risk management strategies are policy issues and involve an interplay of considerations, including technical, social, cultural, political, educational, and economic aspects (US Congress, 1993; van Leeuwen, 2007). Even risk assessment, which has traditionally been understood as solely a scientific matter, is intertwined with societal concerns and values (National Research Council, 2009; Miller and Wickson 2015). For example, the very question of what data is required to suffice regulatory risk assessment and how such data should be generated is fundamentally a political decision (van Leeuwen, 2007). This reduction and recasting of political challenges as technical problems of engineering design implies a paradigm of control that is in contrast to a more nuanced and realistic navigation of complexity and uncertainty. According to the vision of SbD, if we understand $\mathrm{x}$ and do $\mathrm{y}$, we will be able to attain control over the otherwise unruly nano-domain. However, although the application of SbD in the engineering sector is based on mitigation of known risks, 
it is important to note that this is currently not the case for ENMs where the process of developing standards for safety testing is still ongoing (Shatkin and Ong, 2016; Skjolding et al., 2016) and there is no reliable and complete body of knowledge on the risks of ENMs that can simply be incorporated into design processes.

One of the key characteristics of $\mathrm{SbD}$ is that it requires stakeholder collaboration to discuss and respond to potential safety implications throughout the value chain. However, although stakeholder collaboration is arguably desirable, (close) collaboration between scientists researching safety and innovators developing new products can itself create new challenges and concerns, such as the potential for bias in research priorities, tension from diverging power relations among different stakeholders, questions about the freedom to disseminate (negative) results and the distribution of responsibility. These challenges related to the autonomy and independence of scientists can significantly affect the willingness to collaborate and therefore the uptake and realization of SbD in practice and demand careful reflection and deliberation in order to guide collaborations in fruitful, robust and mutually respectful ways. Moreover, it is worth noting that close collaborations between industrial innovators and safety scientists as called for within SbD can affect public trust in the research and products coming out of such collaborations. This has been demonstrated in the case of biotechnology, in which the call has been for improving conditions for greater levels of independent safety research, rather than for more safety research conducted in collaboration with industry (Waltz 2009; Mehta, 2004), or alternatively, that clear lines are established between when collaboration is useful and when independent safety evaluation, audits and quality controls are required (Kapuscinski et al., 2003). 


\section{Drug Discovery and Development}

Throughout the process of inventing and designing new drugs, the pharmaceutical industry addresses toxicity issues from the earliest stages in drug discovery into preclinical and clinical drug development. In drug discovery, high-throughput assays are utilized to screen for toxicity to identify risks early in the innovation process. Most of this early work is considered exploratory and done without good laboratory practices (GLP), whereas later in vivo toxicity testing is targeted to fulfill regulatory demands. This is fundamentally different from the current situation for most ENMs regulated e.g. through $\mathrm{REACH}$, where the focus on testing primarily occurs once they have entered, or are about to enter, the market. Moving away from current regulatory toxicology models and closer to the principles within drug discovery seems to be at the core of how SbD is being envisaged for EMNs.

In drug discovery, early in vitro and in silico screening is used to predict toxicity and avoid safety-related failure downstream in development (including the significant waste of resources this represents) (Ahuja and Sharma, 2014). This is a huge issue in DDD as approximately $90 \%$ of drugs that come through pre-clinical testing fail in the clinical phase (Hay et al., 2014). Approximately one third of this clinical attrition is due to safety concerns (Kola and Landis, 2004) and improving the predictability of failure before entering clinical trials by $10 \%$ is estimated to save a company approximately $\$ 100$ million (Sasseville et al., 2004). This is the foundation of the ‘fail early, fail often’ discovery paradigm in DDD (Blomme and Will, 2016).

Thus, the primary point of 'frontloading' the drug pipeline with early safety tests is to try to reduce future loses. This does not, however, change the need for thorough downstream toxicological evaluation in vivo, nor make the process faster or cheaper (Snodin, 2002; Rang, 2007; Dambach et al., 2016) and, perhaps surprisingly, 
it seems questionable whether the approach has had a significant impact on clinical attrition rates thus far (Blomme and Will, 2016).

The early in vitro screening in DDD can also be denoted as pharmacological profiling as it is done to determine what targets and off-targets a compound interacts with; the classical example being ' $h E R G$ screening' as unintended hERG interference has been one of the most frequent causes for preclinical attrition as well as drug withdrawals (Sanguinetti and Tristani-Firouzi, 2006; Möller, 2010, Danker and Möller, 2014). The approach to avoid hERG related issues was screening potential new drugs in vitro, e.g. in a ligand binding assay, to ensure that marketed drugs do not show affinity to bind to hERG. Such approaches have had an impressive effect, to the point where no new drugs have been withdrawn due to this side-effect since the screenings began (Shah, 2006; Stockbridge et al., 2013; Polak et al., 2015).

However, despite the efforts to address toxicity early (as well as throughout) DDD, the concept of having designed safety into the drug is nonexistent. On the contrary, it is considered a misconception that even all serious adverse drug reactions are known when a new drug reaches the market (FDA, 2016). It is not uncommon that drugs can come through 10-15 years of discovery, development, optimization, testing and finally regulatory approval, only to be withdrawn again because of safety issues that arise during their use. The database WITHDRAWN has collected data on 578 withdrawn drugs and identified safety issues as the main reason for withdrawal in half the cases (Siramshetty et al., 2015). Currently, the probability that a new drug will be withdrawn from the market due to safety issues or receive a new black box warning is estimated to be at 20\% (Lasser et al., 2002). 


\section{What can Nanosafety learn from Drug Development?}

It seems clear that establishing a strategy to screen EMNs with e.g. (Q)SAR and HTS has the possibility of identifying materials with lower intrinsic hazard potential. However, the leap of faith between the ability to identify lower hazard potentials and the ability to design materials to simultaneously maximize safety and functionality in such a way that the resulting material may be called 'safe' seems unjustifiable. A recent example of this is the study by Naatz et al. (2017). Through Fe doping, a hazard reduction was obtained for $\mathrm{CuO}$ particles, which led the authors to conclude that they had demonstrated the particles' 'safe use in the environment'. However, even their safest particle still gives rise to $\mathrm{EC}_{50}$ values below $1 \mathrm{mg} / \mathrm{L}$, which classifies CuO particles as 'very toxic' (Kahru and Dubourguier, 2010).

Furthermore, using a pharmaceutical analogy, finding a material that performs well in HTS might be considered a hit compound, but turning hits into leads requires optimization, and as such, the material is still far from being considered a viable drug candidate and decades from being a commercially available drug. This is not to say that all ENMs should be held to the same safety standard as pharmaceutical drugs, however it emphasizes that true optimization is no trivial task and cannot rely on screening without redesigning and redesigning without screening. Achieving a hazard reduction through optimization without interfering with functionality - if possible requires iterative testing.

What seems more reasonable than bold claims of complete safety is that nanosafety as a science is getting closer to identifying material characteristics or properties linked to hazard or risk potential that should be avoided as much as possible. This could lay the foundation for 'design guidelines' of the type that have had an immense impact on DDD, with the most well-known being Lipinski's rule of 
five (Lipinski et al., 1997), driving development towards more rational drug design (Zhang and Wilkinson, 2007; Leeson, 2012). Although these guidelines for design aim towards optimizing a compound's so-called 'druggability', similar rules exist for avoiding creating compounds with known toxicity (Smith, 2011). Already in 2009, Nel et al. (2009) summarized the mode of action of multiple types of EMNs as well as possible design features to mitigate toxicity. Most notable was the 'fiber pathogenicity paradigm' that recommends against designing persistent high aspect ratio nanoparticles (HARNs) longer than $5 \mu \mathrm{m}$ and wider than $3 \mu \mathrm{m}$ (Donaldson et al., 2011). Similarly, Yan et al. (2011) proposed five properties for carbon nanomaterial design to reduce toxicity, such as adding hydrophilic surface modifications. Other examples include metal doping strategies (Wake et al., 2004; George et al., 2010, Naatz et al., 2017), modifying particle surface charge (Harper et al., 2011; Fröhlich, 2012; Gilbertson et al. 2016) as well as shape considerations (Forest et al. 2017). Being aware of this type of knowledge when developing new materials seems paramount, although the impact such guidelines have on the actual practice of innovation and the commercialization of products utilizing nanomaterials remains to be demonstrated. It is also crucial to note that such guidelines remain a starting point for product design that still require empirical testing.

In DDD the focus of risk mitigation naturally revolves around hazard reduction, as exposure considerations for pharmaceuticals are limited. Implementing a SbD concept, inspired from DDD, appears to have created a bias in nanosafety research. As seen in Table 1, all but one EU project on SbD addresses hazard, whereas only a few have a focus on the exposure and fate of ENMs. Reducing hazard may certainly be possible in some cases, however, it is highly unlikely to be achievable for all applications as it can clash with the desired functionality of the 
material. For example, ENMs developed to remediate polluted environments, should ideally be both mobile and reactive when seen from a performance perspective and yet, these are exactly the same characteristics that are undesirable from an environmental safety perspective (Karn et al., 2009). Optimization therefore always requires carefully considering and balancing functionality and toxicity. For instance, for $\mathrm{ZnO}$ particles a metal doping strategy can effectively be used to decrease dissolution and thereby toxicity (Xia et al., 2011). However, as emphasized by Sotiriou et al. (2014), this unfortunately interferes with the transparency of the particles as needed in e.g. sunscreen applications. Sotiriou et al. (2014) demonstrated that $\mathrm{ZnO}$ particles can instead be coated with a thin layer of $\mathrm{SiO}_{2}$ that can maintain the desired optical properties while still reducing toxicity. However, coating particles in e.g. $\mathrm{SiO}_{2}$ "cannot be considered a "swiss army knife" for all ENMs and all applications' (Gass et al., 2013). The current enthusiasm being shown for SbD in nanosafety research projects and policy in Europe usually fails to acknowledge that there is a fundamental challenge involved in trying to maximize both functionality and safety for all ENM applications. This undermines the potential value of the concept because it promotes an unrealistic ideal of universal applicability and potential without engaging in serious considerations of where the concept may be useful and where other approaches to minimizing harm may also be required.

As noted by Hjorth et al. (2017), exposure considerations may in some cases be a more obvious starting point for improving the safety profile of ENMs. Furthermore, as hazard has proven difficult to assess in nanotoxicology and linking e,g, unwanted ROS generation to particles properties is at times even noted as controversial (von Moos and Slaveykova, 2014), other warning signs such as novelty, persistency, dispersibility and the possibility of bioaccumulation or irreversible 
actions should also be taken into account when addressing the potential harmful properties of ENMs (Hansen et al., 2013). Similarly, other decision support tools also exist for near-term decision-making (Som et al., 2013).

Besides pharmaceuticals, early safety screening is also set in place in the development of pesticides. Again, as the process of obtaining regulatory approval of pesticides is expensive and requires a demanding safety evaluation (Damalas and Eleftherohorinos, 2011), the industry tries to limit late-stage rejections due to safety concerns. In contrast to pharmaceuticals and pesticides, ENMs do not necessarily trigger any special regulatory safety testing requirements. On the contrary, different ENMs will be handled by very different regulations based on their use and product category. Therefore, the requirements for safety testing can vary considerably and encouraging an early toxicity evaluation risks being an undesirable financial burden unless the material is forced to go through an even costlier safety assessment to obtain market access.

Although it is rarely explicitly claimed that SbD can replace regulatory risk assessment for ENMs, when it is presented as a way for nanosafety to keep pace with innovation, there is an implicit assumption that it will not just create a host of new testing demands prior to the needs of regulatory toxicology, but that it will somehow reduce the time and load of work required for 'regulatory preparedness' and risk analysis.

However, all of this relies on the predictive capacity of simplified testing. Going back to pharmacological profiling, it is today recognized that hERG is a 'promiscuous' target causing binding screenings to be too simplistic, quite conservative and giving rise to too many false positives (Möller, 2010; Polak et al., 2015). So although, the screening has been effective in stopping potentially risky drug 
candidates, it is actually not very predictive and consequently potentially good drugs have been missed (Blomme and Will, 2016). More nuanced and sophisticated screenings with better predictability call for a shift in paradigm towards integrated in vitro and in silico methods based solely on a mechanistic understanding (Sager et al., 2014; Frommeyer and Eckardt, 2016).

Much effort is similarly currently invested in advancing nanotoxicology to be able to improve in silico and in vitro predictability based on a mechanistic foundation. Especially the identification of adverse outcome pathways (AOP) has received much attention to help in vitro to in vivo extrapolation and fill knowledge gaps in nanotoxicology (Gerloff et al., 2016). However, nanotoxicology is still struggling with fundamental issues in experimental testing, giving rise to experimental data of variable quality and hampering the generation of predictive models, such as QSARs (Tantra et al., 2015). A similar concern has also been articulated by the NSC in the European Commission's research strategy for nanosafety in Horizon 2020. E.g. 'Current resources or test methods are not likely to enable safety assessment of the numerous novel nanomaterials...' and 'we still lack a fundamental understanding of how nanomaterials interact with living systems and, thus, we are not yet in a position to assess the relevant end-points for nanomaterial toxicity’ (Savolainen et al., 2013). The working group on SbD in the NSC directly states that SbD has not been applied to ENMs 'primarily because nanosafety research is not yet robust enough to operate in a predictive manner' (Lynch, 2016).

SbD seems to go straight towards 'ensuring safety' in response to, and in spite of, these problems. However, reliable testing arguably precedes hazard identification, while hazard identification precedes mechanistic understanding, mechanistic understanding precedes prediction and prediction precedes 'SbD'. Or simply, SbD 
cannot be used to circumvent the issues we are currently facing in developing robust risk analysis for ENMs.

\section{Conclusion}

Safety is not an inherent material property. It goes against even the most fundamental concepts in toxicology to propose that it is. 'All things are poison and nothing is without poison' is as true today as when Paracelsus stated it in the $16^{\text {th }}$ century. Perhaps this central contradiction in SbD is well understood by nanotoxicologists; however it could fool other stakeholders and lead them to consequently have unrealistic expectations as to what can be achieved through SbD. The novelty of ENMs and the limitations of our existing knowledge and test methods have meant that ENMs have proven difficult to adequately risk assess and consequently risk manage however SbD cannot remediate or replace this. In DDD, early in vitro or in silico screening is used as a risk reduction or risk mitigation strategy, which is ultimately followed by detailed toxicological testing and regulation, and a simulation of the approach in nanosafety would best adopt a similar approach. From DDD we should realize that 'SbD' can only be considered a starting point rather than the end point on the road towards developing innovative new products that are safe for human health and the environment.

Risk identification, reduction and mitigation should of course be encouraged. Having safety considerations in mind throughout research and development and early identification of safer alternatives is indeed imperative and should be supported, e.g. through the implementation of approaches such as alternatives assessment (Hjorth et al., 2017). Addressing fate and exposure in design considerations (in addition to the currently predominating focus on hazard reduction) should also have a higher priority. 
DDD has taught us that despite the best intentions and the best design, no drug is without side effects. Likewise, no ENM can be designed to be safe for all organisms and systems under all contexts and conditions of use. Overcoming the challenges facing ENM regulation and the obstacles within risk-based research to fast-track nanosafety cannot be achieved through high ambitions alone. The nanosafety field would do well to learn from DDD and temper its expectations and claims regarding SbD with open acknowledgement of its limitations and challenges in practice.

\section{Acknowledgements}

The authors would like to thank Torsten Fleischer for helpful comments on an early draft and the NorNANoREG project (project \#2391199/070) funded by the Research Council of Norway for funding FW.

\section{Declaration of interest}

The authors declare no conflict of interest.

\section{References}

Ahuja, V. and Sharma, S., 2014. Drug safety testing paradigm, current progress and future challenges: An overview. Journal of Applied Toxicology, 34 (6), 576-594.

Blomme, E.A.G. and Will, Y., 2016. Toxicology Strategies for Drug Discovery: Present and Future. Chemical Research in Toxicology, 29 (4), 473-504.

Brown, D.B., 1976. Systems Analysis and Design for Safety: Safety Systems Engineering. Prentice Hall. Upper Saddle River (NJ), US.

Burello, E. and Worth, A.P., 2015. A rule for designing safer nanomaterials: do not interfere with the cellular redox equilibrium. Nanotoxicology, 9 (1), 116117.Costa, A.L., 2016. Chapter 10 Applying Safety by Molecular Design Concepts to Nanomaterials Risk Management. In: Manageing risk in nanotechnology. Topics in governance, assurance and transfer (Eds Murphy, F., McAlea, E.M., Mullins, M.,) Springer International Publishing, Dordrecht, The Netherlands.

Damalas, C.A. and Eleftherohorinos, I.G., 2011. Pesticide exposure, safety issues, and risk assessment indicators. International Journal of Environmental Research and Public Health, 8 (5), 1402-1419. 
Dambach, D.M., Misner, D., Brock, M., Fullerton, A., Proctor, W., Maher, J., Lee, D., Ford, K., and Diaz, D., 2016. Safety Lead Optimization and Candidate Identification: Integrating New Technologies into Decision-Making. Chemical Research in Toxicology, 29 (4), 452-472.

Damoiseaux, R., George, S., Li, M., Pokhrel, S., Ji, Z., France, B., Xia, T., Suarez, E., Rallo, R., Mädler, L., Cohen, Y., Hoek, E.M.V., and Nel, A., 2011. No time to lose--high throughput screening to assess nanomaterial safety. Nanoscale, 3 (4), 1345-60.

Danker, T. and Möller, C., 2014. Early identification of hERG liability in drug discovery programs by automated patch clamp. Frontiers in Pharmacology, 51 11.

Donaldson, K., Murphy, F., Schinwald, A., Duffin, R., and Poland, C.A., 2011. Identifying the pulmonary hazard of high aspect ratio nanoparticles to enable their safety-by-design. Nanomedicine, 6 (1), 143-56.

Fadeel, B., Nel, A., Dobson, P., Aitken, R., Dawson, K., Kreyling, W., Mädler, L., Katalagarianakis, G., Pykkö, I., and Schrotter, J. C., 2011. Chapter 4.9.1 International perspectives from the overseas workshops (US-European Union Workshop). In: Nanotechnology Research Directions for Societal Needs in 2020. Retrospective and Outlook (Eds Roco, M.C., Mirkin, C.A. and Hersam, M.C.) , Springer, Dordrecht, The Netherlands.

Fadeel, B., 2013. Nanosafety : towards safer design of nanomedicines. Journal of internal medicine, 578-580.

FDA, 2016. Preventable Adverse Drug Reactions: A Focus on Drug Interactions [Webpage]. Available at http://www.fda.gov/Drugs/DevelopmentApprovalProcess/DevelopmentResource s/DrugInteractionsLabeling/ucm110632.htm. (Accessed November 1 2016). US Food and Drug Administration.

Forest, V., Leclerc, L., Hochepied, J.-F., Trouvé, A., Sarry, G., and Pourchez, J., 2017. Impact of cerium oxide nanoparticles shape on their in vitro cellular toxicity. Toxicology in Vitro, 38, 136-141. Frommeyer, G. and Eckardt, L., 2016. Drug-induced proarrhythmia: risk factors and electrophysiological mechanisms. Nature Reviews cardiology, 13, 36-47.

Fröhlich, E., 2012. The role of surface charge in cellular uptake and cytotoxicity of medical nanoparticles. International Journal of Nanomedicine, 7, 5577-5591.

Gass, S., Cohen, J.M., Pyrgiotakis, G., Sotiriou, G.A., Pratsinis, S.E., and Demokritou, P., 2013. Safer formulation concept for flame-generated engineered nanomaterials. ACS Sustainable Chemistry and Engineering, 1, 843-857.

George, S., Pokhrel, S., Xia, T., Gilbert, B., Ji, Z., Schowalter, M., Rosenauer, A., Damoiseaux, R., Bradley, K.A., Mädler, L., and Nel, A.E., 2010. Use of a rapid cytotoxicity screening approach to engineer a safer zinc oxide nanoparticle through iron doping. ACS nano, 4 (1), 15-29.

Geraci, C., Heidel, D., Sayes, C., Hodson, L., Schulte, P., Eastlake, A., and Brenner, S., 2015. Perspectives on the design of safer nanomaterials and manufacturing processes. Journal of Nanoparticle Research, 17 (9), 1-13.

Gerloff, K., Landesmann, B., Worth, A., Munn, S., Palosaari, T., and Whelan, M., 2016. The Adverse Outcome Pathway approach in nanotoxicology.

Computational Toxicology, 1-9.

Gilbertson, L.M., Melnikov, F., Wehmas, L.C., Anastas, P.T., Tanguay, R.L., and Zimmerman, J.B., 2016. Toward safer multi-walled carbon nanotube design: Establishing a statistical model that relates surface charge and embryonic 
zebrafish mortality. Nanotoxicology,10 (1), 10-19Grieger, K.D., 2011.

Understanding and assessing potential environmental risks of nanomaterials:

Emerging rools for emerging risks. PhD Thesis, Technical University of

Denmark, Kgs. Lyngby, Denmark.

Hansen, S.F. and Baun, A., 2015. DPSIR and Stakeholder Analysis of the Use of Nanosilver. Nanoethics, 9 (3), 297-319.

Hansen, S.F., Nielsen, K.N., Knudsen, N., Grieger, K.D., and Baun, A., 2013. Operationalization and application of 'early warning signs' to screen nanomaterials for harmful properties. Environmental Sciences: Processes and Impacts, 15 (1), 190-203.

Harper, S.L., Carriere, J.L., Miller, J.M., Hutchison, J.E., Maddux, B.L.S., and Tanguay, R.L., 2011. Systematic evaluation of nanomaterial toxicity: utility of standardized materials and rapid assays. ACS nano, 5 (6), 4688-97.

Hay, M., Thomas, D.W., Craighead, J.L., Economides, C., and Rosenthal, J., 2014. Clinical development success rates for investigational drugs. Nature Biotechnology, 32 (1), 40-51.

Hjorth, R., Hansen, S.F., Jacobs, M., Tickner, J., Ellenbecker, M., and Baun, A., 2017. The applicability of chemical alternatives assessment for engineered nanomaterials. Integrated environmental assessment and management. DOI: 10.1002/ieam.1762.

ICON, 2010. Advancing the Eco-Responsible Design and Disposal of Engineered Nanomaterials. International Council on Nanotechnology (ICON). Houston, Texas.

Johnston, H., Pojana, G., Zuin, S., Jacobsen, N.R., Møller, P., Loft, S., SemmlerBehnke, M., McGuiness, C., Balharry, D., Marcomini, A., Wallin, H., Kreyling, W., Donaldson, K., Tran, L., and Stone, V., 2013. Engineered nanomaterial risk. Lessons learnt from completed nanotoxicology studies: potential solutions to current and future challenges. Critical reviews in toxicology, 43, 1-20.

Kahru, A. and Dubourguier, H.-C., 2010. From ecotoxicology to nanoecotoxicology. Toxicology, 269 (2-3), 105-19.

Kapuscinski, A. R., Goodman, R.M., Hann, S.D., Jacobs, L.R., Pullins, E.E., Johnson, C. S., Kinsey, J.D., Krall, R.L., La Vina, A.G.M., Mellon, M.G. and Ruttan, V. W., 2003. Making'safety first'a reality for biotechnology products. Nature biotechnology, 21, 599-601.

Karn, B., Kuiken, T., and Otto, M., 2009. Nanotechnology and in situ remediation: a review of the benefits and potential risks. Environmental health perspectives, 117 (12), 1813-31.

Kelty, C.M., 2009. Beyond Implications and Applications: the Story of 'Safety by Design'. Nanoethics, 3 (2), 79-96.

Kola, I. and Landis, J., 2004. Can the pharmaceutical industry reduce attrition rates? Nature reviews. Drug discovery, 3, 1-5.

Lasser, K.E., Allen, P.D., Wollhandler, S.J., Himmelstein, D.U., Wolfe, S.M., and Bor, D.H., 2002. Timing of New Black Box Warnings and Withdrawals for Prescription Medications. Jama, 287 (17), 2215-2220.

Le, T.C., Yin, H., Chen, R., Chen, Y., Zhao, L., Casey, P.S., Chen, C., and Winkler, D.A., 2016. An Experimental and Computational Approach to the Development of ZnO Nanoparticles that are Safe by Design. Small, (26), 3568-3577.Leeson, P., 2012. Chemical beauty contest. Nature. 481. 455-456.

Lehman, S.E., Morris, A.S., Mueller, P.S., Salem, A.K., Grassian, V.H., and Larsen, S.C., 2016. Silica nanoparticle-generated ROS as a predictor of cellular toxicity: 
Mechanistic insights and safety by design. Environmental Science: Nano, 3 (1), 56-66.

van Leeuwen, C.J., 2007 General Introduction. In: Risk Assessment of Chemicals: An Introduction (Eds van Leeuwen, C.J. \& Vermeire T.G.). Second Edition. Springer, Dordrecht, The Netherlands.

Lipinski, C.A., Lombardo, F., Dominy, B.W., and Feeney, P.J., 1997. Experimental and computational approaches to estimate solubility and permeability in drug discovery and development settings. Advanced Drug Delivery. (23). 3-25.

Lynch, I., 2014. Compendium of Projects in the European NanoSafety Cluster. 2014 edition. http://goo.gl/4d6Bqo

Lynch, I., 2015. Compendium of Projects in the European NanoSafety Cluster. 2015 edition. http://goo.gl/p3Qo50

Lynch, I., 2016. Compendium of Projects in the European NanoSafety Cluster, 2016 edition.

http://www.nanosafetycluster.eu/www.nanosafetycluster.eu/home/europeannanosafety-cluster-compendium.html.

Lynch, I., Weiss, C., and Valsami-Jones, E., 2014. A strategy for grouping of nanomaterials based on key physico-chemical descriptors as a basis for safer-bydesign NMs. Nano Today, 9 (3), 266-270.

Mehta, M., 2004. "From Biotechnology to Nanotechnology: What Can We Learn from Earlier Technologies?" Bulletin of Science, Technology \& Society (24) 34-39.

Miller, G. and Wickson, F., 2015. Risk Analysis of Nanomaterials: Exposing Nanotechnology's Naked Emperor. Review of Policy Research, 32 (4), 485-512.

Möller, C., 2010. Keeping the Rhythm: hERG and Beyond in Cardiovascular Safety Pharmacology. Expert Review of Clinical Pharmacology, 3 (3), 321-329.

Naatz, H., Lin, S., Li, R., Jiang, W., Ji, Z., Chang, C.H., Köser, J., Thöming, J., Xia, T., Nel, A.E., Mädler, L., and Pokhrel, S., 2017. Safe-by-Design CuO Nanoparticles via Fe-Doping, $\mathrm{Cu}-\mathrm{O}$ Bond Length Variation, and Biological Assessment in Cells and Zebrafish Embryos. ACS Nano, 11 (1), 501-515.

NANoREG, 2015. Comparison on toxicity testing in drug development and in present MNMs safety testing. Deliverable 6.3 Available at http://www.nanoreg.eu/media-and-downloads/factsheets-of-nanoregoutput/230-deliverabe-6-3-comparison-on-toxicity-testing-in-drugdevelopment-and-in-present-mnms-safety-testing.

National Research Council, 2009. Summary. In: Science and Decisions: Advancing Risk Assessment. Washington, DC: The National Academies Press, 1-14.

Nel, A.E., Mädler, L., Velegol, D., Xia, T., Hoek, E.M. V, Somasundaran, P., Klaessig, F., Castranova, V., and Thompson, M., 2009. Understanding biophysicochemical interactions at the nano-bio interface. Nature materials, 8 (7), 543-57.

Nel, A., Xia, T., Meng, H., Wang, X., Lin, S., Ji, Z., and Zhang, H., 2013. Nanomaterial toxicity testing in the 21st century: use of a predictive toxicological approach and high-throughput screening. Accounts of Chemical Research, 46 (3), 607-621.

NSC, 2016. European NanoSafety Cluster Compendium [Webpage]. Available from http://www.nanosafetycluster.eu/www.nanosafetycluster.eu/home/europeannanosafety-cluster-compendium.html. (accessed November 1 2016). Nanosafety Cluster.

Meng, H., Xia, T., George, S., and Nel, A.E., 2009. A Predictive Toxicological 
Paradigm for the Safety Assessment of Nanomaterials. ACS Nano, 3 (7).

Morose, G., 2010. The 5 principles of 'Design for Safer Nanotechnology'. Journal of Cleaner Production, 18 (3), 285-289.

Movia, D., Gerard, V., Maguire, C.M., Jain, N., Bell, A.P., Nicolosi, V., O’Neill, T., Scholz, D., Gun'ko, Y., Volkov, Y., and Prina-Mello, A., 2014. A safe-by-design approach to the development of gold nanoboxes as carriers for internalization into cancer cells. Biomaterials, 35 (9), 2543-57.

Polak, S., Pugsley, M.K., Stockbridge, N., Garnett, C., and Wiśniowska, B., 2015. Early Drug Discovery Prediction of Proarrhythmia Potential and Its Covariates. The AAPS journal, 17 (4), 1025-32.

Rang, H.P., 2007. Assessing drug safety. In: Drug discovery and development. Technology in transition (Eds Rang, H.P.). Reprint 2007, Churchill Livingstone Elsevier.

Riediker, M., 2011. Coordination and Collaboration in European Research towards Healthy and Safe Nanomaterials. Journal of Physics: Conference Series, 304 (1)

Sager, P.T., Gintant, G., Turner, J.R., Pettit, S., and Stockbridge, N., 2014. Rechanneling the cardiac proarrhythmia safety paradigm: A meeting report from the Cardiac Safety Research Consortium. American Heart Journal, 167 (3), 292300.

Saleh, N.B., Aich, N., Plazas-Tuttle, J., Lead, J.R., and Lowry, G. V., 2015. Research strategy to determine when novel nanohybrids pose unique environmental risks. Environ. Sci.: Nano, 2 (1), 11-18.

Sanguinetti, M.C. and Tristani-Firouzi, M., 2006. hERG potassium channels and cardiac arrhythmia. Nature, 440 (7083), 463-469.

Sasseville, V.G., Lane, J.H., Kadambi, V.J., Bouchard, P., Lee, F.W., Balani, S.K., Miwa, G.T., Smith, P.F., and Alden, C.L., 2004. Testing paradigm for prediction of development-limiting barriers and human drug toxicity. Chemico-Biological Interactions, 150 (1), 9-25.

Savolainen, K., Backman, U., Brouwer, D., Fadeel, B., Fernandes, T., Kuhlbusch, T., Landsiedel, R., Lynch, I., and Pylkkänen, L., 2013. Nanosafety in Europe 20152025: Towards Safe and Sustainable Nanomaterials and Nanotechnology

Innovations. Finnish Institute of Occupational Health, EDITA, Helsinki, Finland

Shah, R., 2006. Can pharmacogenetics help rescue drugs withdrawn from the market? Pharmacogenomics, 7 (6), 889-908.

Shatkin, J.A. and Ong, K.J., 2016. Alternative Testing Strategies for Nanomaterials: State of the Science and Considerations for Risk Analysis. Risk Analysis. DOI: 10.1111/risa.12642

Sips, A., Noorlander, C., Lehmann, H.C. \& Höhener, K., 2015. NANoREG Safe-byDesign (SbD) Concept. Available at http://www.nanoreg.eu/media-anddownloads/publications/258-nanoreg-safe-by-design-sbd-concept.

Siramshetty, V.B., Nickel, J., Omieczynski, C., Gohlke, B., Drwal, M.N., and Preissner, R., 2015. WITHDRAWN - a resource for withdrawn and discontinued drugs. Nucleic Acids Research, 43 (20), 1-7.

Skjolding, L.M., Sørensen, S.N., Hartmann, N.B., Hjorth, R., Hansen, S.F., and Baun, A., 2016. A Critical Review of Aquatic Ecotoxicity Testing of Nanoparticles The Quest for Disclosing Nanoparticle Effects. Angewandte Chemie International Edition. DOI: 10.1002/anie.201604964.

Smith, G.F., 2011. Designing drugs to avoid toxicity. Progress in Medicinal Chemistry. DOI 10.1016/B978-0-12-381290-2.00001-X.

Snodin, D.J., 2002. An EU perspective on the use of in vitro methods in regulatory 
pharmaceutical toxicology. Toxicology Letters, 127 (1-3), 161-168.

Som, C., Nowack, B., Krug, H.F., and Wick, P., 2013. Toward the development of decision supporting tools that can be used for safe production and use of nanomaterials. Accounts of Chemical Research, 46 (3), 863-872.

Sotiriou, G.A., Watson, C., Murdaugh, K.M., Darrah, T.H., Watson, C., Kimberly, M., Elder, A., and Brain, J.D., 2014. Engineering safer-by-design silica-coated $\mathrm{ZnO}$ nanorods with reduced DNA damage potential. Environmental Science: Nano, 1(2), 144-153.

Stockbridge, N., Morganroth, J., Shah, R.R., and Garnett, C., 2013. Dealing with global safety issues: Was the response to QT-liability of non-cardiac drugs well coordinated? Drug Safety, 36 (3), 167-182.Tantra, R., Oksel, C., Puzyn, T., Wang, J., Robinson, K.N., Wang, X.Z., Ma, C.Y., and Wilkins, T., 2015. Nano(Q)SAR: Challenges, pitfalls and perspectives. Nanotoxicology, 5390, 636642.

Tinkle, S.S., 2010. Maximizing safe design of engineered nanomaterials : the NIH and NIEHS research perspective. WIREs Nanomedicine and nanobiotechnology, 2 (1), 88-98.

Truong, L., Simonich, M.T., Saili, K.S., and Tanguay, R.L., 2012. Fishing to Design Inherently Safer Nanoparticles. In: Zebrafish: Methods for Assessing Drug Safety and toxicity (eds McGrath, P), John Wiley \& Sons, INC. Hoboken, New Jersey, USA.

US Congress, 1993. Researching health risks. OTA-BBS-571. Office of Technology Assessment, Washington (DC). US.

von Moos, N. and Slaveykova, V.I., 2014. Oxidative stress induced by inorganic nanoparticles in bacteria and aquatic microalgae--state of the art and knowledge gaps. Nanotoxicology, 8 (6), 605-630.

Wake, G., Lipscomb, S., Holland, E., and Knowland, J., 2004. The effects of manganese doping on UVA absorption and free radical generation of micronised titanium dioxide and its consequences for the photostability of UVA absorbing organic sunscreen components. Photochem. Photobiol. Sci., 648-652.

Waltz, E., 2009. Under wraps: are the crop industry's strong-arm tactics and closefisted attitude to sharing seeds holding back independent research and undermining public acceptance of transgenic crops?, Nature Biotechnology, 27, 880-883.

Wang, J., Ruxton, T., and Labrie, C.R., 1996. Design for safety of engineering systems with multiple failure state variables. Reliability Engineering and System Safety, 50 (1995), 271-284.

Xia, T., Zhao, Y., Sager, T., George, S., Pokhrel, S., Li, N., Schoenfeld, D., Meng, H., Lin, S., Wang, X., Wang, M., Ji, Z., Zink, J.I., Mädler, L., Castranova, V., Lin, S., and Nel, A.E., 2011. Decreased dissolution of $\mathrm{ZnO}$ by iron doping yields nanoparticles with reduced toxicity in the rodent lung and zebrafish embryos. ACS Nano, 5 (2), 1223-1235.

Yan, L., Zhao, F., Li, S., Hu, Z., and Zhao, Y., 2011. Low-toxic and safe nanomaterials by surface-chemical design, carbon nanotubes, fullerenes, metallofullerenes, and graphenes. Nanoscale, 3, 362-382.

Zhang, M.Q. and Wilkinson, B., 2007. Drug discovery beyond the 'rule-of-five'. Current Opinion in Biotechnology, 18 (6), 478-488. 
Table 1 Overview and focus of the projects in the 2016 Nanosafety Cluster Compendium that address Safety by design (SbD) (our highlights). The exes indicate whether the projects are involved in the conceptually idea behind SbD and whether safety is approached through hazard, exposure and/or fate considerations.

Projects

\begin{tabular}{|c|c|c|}
\hline \multirow{5}{*}{ 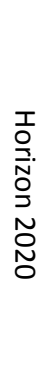 } & SmartNanoTox & $\begin{array}{l}\text { 'By scanning main groups of engineered NMs, we will identify the NM proper } \\
\text { AO, and thus should be modified or avoided. This will provide means of group } \\
\text { are safe by design' }\end{array}$ \\
\hline & NanoFase & $\begin{array}{l}\text { [activities in NanoFase] 'will aid Safe by Design and Benign by Design Concept } \\
\text { form(s) and distribution following environmental release, allowing this to be }\end{array}$ \\
\hline & NANOGENTOOLS & 'Conduct research and training on biophysical techniques and mathematica \\
\hline & ProSafe & [one objective is to] 'Acceptance and further elaboration of the NANoRE \\
\hline & NANOREG II & $\begin{array}{l}\text { 'The NANoREG II project, built around the challenge of coupling SbD to the r } \\
\text { from value chain implementation studies to establish SbD as a fundamental }\end{array}$ \\
\hline \multirow{7}{*}{ 守 } & eNanoMapper & $\begin{array}{l}\text { '...we will develop resources, tools and standards for a scientifically sound r } \\
\text { ENMs as well as the assessment of existing materials' }\end{array}$ \\
\hline & $\begin{array}{l}\text { FutureNanoNee } \\
\text { ds }\end{array}$ & $\begin{array}{l}\text { [one objective is] 'To develop an understanding of the relationships betwee } \\
\text { environmental activity (that is, structure and 'identity' broadly defined) the }\end{array}$ \\
\hline & GUIDEnano & $\begin{array}{l}\text { 'SbD strategies were intended to : re-design relevant physicochemical proper } \\
\text { functionality within the NM enabled product, avoid or reduce the release of } \\
\text { compatibility between NM and matrix, to lower the possibility of environmen } \\
\text { exposure to NM by designing and synthesizing less reactive and/or less persis }\end{array}$ \\
\hline & NanoMILE & $\begin{array}{l}\text { 'NanoMILE intends to revolutionise nanosafety research through its robust } \\
\text { technically and computationally advanced integration of systems biology, it } \\
\text { novel high throughput platforms for screening and its feedback loops for de }\end{array}$ \\
\hline & NanoToxClass & $\begin{array}{l}\text { 'NanoToxClass also enhances our understanding of modes of action for NM at } \\
\text { the most predictive ones (which will be then used as a basis for grouping). On } \\
\text { the determination of adverse outcome pathways (AOP). Finally, this knowled } \\
\text { approaches)' }\end{array}$ \\
\hline & SUN & $\begin{array}{l}\text { 'The SUN approach has covered the entire lifecycles of real nanoproducts, ain } \\
\text { innovators to design greener nanotechnologies' }\end{array}$ \\
\hline & NANOREG & 'An integrated research strategy which addresses product/material design \\
\hline
\end{tabular}

\section{Statement}

es that might be responsible for causing a particular toxic effect and lead to a particular 
